\title{
Coil Embolization of Intracranial Aneurysms: A Six-Month Follow-Up Study
}

\author{
Mojtaba Miri, Hossein Ghanaati, ${ }^{1,2}$ Payman Salamati, ${ }^{2}$ Hojat Ebrahimi Nik, ${ }^{1}$ Amir Hossein \\ Jalali, ${ }^{1,}$ Mina Saeednejad, ${ }^{3}$ and Kavous Firouznia ${ }^{1}$
}

${ }_{1}^{1}$ Advanced Diagnostic and Interventional Radiology Research Center (ADIR), Imam Khomeini Hospital, Tehran University of Medical Sciences, Tehran, Iran

${ }^{2}$ Sina Trauma and Surgery Research Center, Sina Hospital, Tehran University of Medical Sciences, Tehran, Iran

3 Islamic Azad University, Tehran Medical Branch, Tehran, Iran

${ }^{*}$ Corresponding author: Amir Hossein Jalali, Advanced Diagnostic and Interventional Radiology Research Center (ADIR), Imam Khomeini Hospital, Tehran University of Medical Sciences, Tehran, Iran. Tel:+98-2166581579, Fax:+98-2166581578, E-mail: amirjalali51@yahoo.com

Received: February 27, 2013; Revised: December 21, 2013; Accepted: April 26, 2014

\begin{abstract}
Background: Rupture of the intracranial aneurysms is associated with a high risk of bleeding and a high incidence of mortality if left untreated.

Objectives: The aim of this study is to report our experience in managing intracranial aneurysms using coil embolization and to report the 6-month follow-up outcome of the patients.

Patients and Methods: From January 2010 to December 2012, a series of 90 nonrandomized consecutive patients (mean age: $44.6 \pm 14.9$ years) with intracranial aneurysms underwent endovascular coil embolization in our center. We excluded patients with dissecting, blood blister-like, or false aneurysms. All patients were evaluated by four-vessel angiography to determine the shape, size, number and location of the aneurysms. We recommended a six-month follow-up control angiography. However, only 38 of them participated in this follow-up imaging. The data were analyzed by chi-square, fisher exact and t-tests and alpha was considered lower than $5 \%$.

Results: Immediately after the procedure, the total occlusion was seen in 76 (86.4\%), subtotal occlusion in six (6.8\%), and partial occlusion in six patients (6.8\%). There was no significant relationship between the aneurysm size, aneurysm neck size, and location of the aneurysm with total or subtotal occlusions. Eleven patients (12.5\%) experienced some complication during the procedure including two tears, three focal neurological signs, three vision disturbances, and three bleedings in the aneurysm. Major complications were significantly higher in the posterior aneurysm compared to the anterior ones ( $55.6 \%$ versus $44.4 \%$ of the major complications; P value $=0.015$ ). Among patients who underwent control angiography, 34 patients (89.4\%) had no change, two (5.3\%) had new growth and two (5.3\%) had widening of the neck after 6 months follow-up. Although aneurysms that remained unchanged after six months follow-up angiography had total occlusion after the procedure, it was 50\% for aneurysms that had any changes in 6 months follow-up angiography (P value $=0.01$ ).

Conclusion: Coil embolization showed successful outcomes in the treatment of intracranial aneurysms with a low complication rate.
\end{abstract}

Keywords: Intracranial Aneurysm; Endovascular Procedure; Follow-Up

\section{Background}

Intracranial aneurysms are a major life-threatening problem that requires surgical or interventional treatment. Ruptures of intracranial aneurysms are devastating, because half of the patients die and up to half of those who survive are disabled (1). Rupture of intracranial aneurysm causing subarachnoid hemorrhage (SAH) occurs in six to eight cases per 100,000 patients in the western population (2). Neurosurgical procedures that clip the aneurysm and prevent further bleeding may have both risks and benefits (3).

After the international subarachnoid aneurysm trial (ISAT), coil embolization has been widely applied for treatment of intracranial aneurysms (4). In ISAT that studied patients with ruptured intracranial aneurysms, the authors showed that endovascular coiling of ruptured intracranial aneurysm was associated with an improved outcome when compared with surgical clipping (24\% versus $31 \%$ morbidity or severe disability) (5).
This treatment technique proved to be effective in preventing rebleeding after aneurysmal rupture $(6,7)$ and showed an even better clinical outcome in terms of disability-free survival as compared with surgical clipping (8). There are some studies in the literature that evaluated outcomes of this procedure in the world, but there is no any study that demonstrates the feasibility and clinical efficacy of coil embolization in the management of patients with cerebral aneurysm in Iran.

\section{Objectives}

The purpose of our study was to report our experience in managing intracranial aneurysms using coil embolization and to report the 6-month outcomes of this technique.

\section{Patients and Methods}

From January 2010 to December 2012, a series of 90 con-

Copyright (C) 2015, Tehran University of Medical Sciences and Iranian Society of Radiology. This is an open-access article distributed under the terms of the Creative Commons Attribution-NonCommercial 4.0 International License (http://creativecommons.org/licenses/by-nc/4.0/) which permits copy and redistribute the material just in noncommercial usages, provided the original work is properly cited. 
Miri M et al.

secutive patients with intracranial aneurysms who were referred by neurosurgeons underwent endovascular coil embolization in our center. The mean age of our patients was $44.6 \pm 14.9(1-79)$ years. This study was approved by our institutional review board. Written informed consent was obtained from all patients.

Patients with dissecting, blood blister-like, or false aneurysms were excluded from the study. Initially, all the patients were evaluated by four-vessel angiography (GE4100 innova flat panel Advantex) to determine the shape, size, count and location of the aneurysms and to decide about the therapeutic protocol. Thereafter, micro catheter $150 \mathrm{~cm}$ was used with a guiding catheter to place the optimal coils in the aneurysm region. First, the 3D helix coil was introduced and thereafter, 2D helix and soft coils were introduced in the aneurysm. For the cases with wide aneurysms, initially the neck of the aneurysm was narrowed with neuroform stent and then the coils were introduced.

In patients taking aspirin for medical conditions, aspirin was maintained until the morning of the procedure. A bolus of $3000 \mathrm{IU}$ heparin was prescribed after femoral artery sheath placement and intermittent boluses of 1000 IU heparin per hour were then administered with monitoring of the activated clotting time.

Conventional post-embolization angiography (femoral) was done to evaluate the effect of aneurysm occlusion, the blood flow of the artery and its intracranial branches and the patients were divided into three groups: total occlusion, subtotal occlusion, and partial occlusion. After six months, the angiography was repeated and aneurysm size, neck widening and shape of the aneurysm were evaluated. Finally, the data were analyzed using SPSS version 16.0. (SPSS Inc., Chicago, Illinois, USA) Chi square and fisher-exact tests were used and were considered statistically significant at $\mathrm{P}$ values less than 0.05 .

\section{Results}

\subsection{Baseline Data}

Clinical and demographic data of the patients are summarized in Table 1.

\subsection{Coiling Results}

In 62 patients, the procedures were performed under general anesthesia. The aneurysms were located in the posterior circulation in 17 patients (19.8\%) and in the anterior circulation in 69 (80.2\%). The characteristics of aneurysms are shown in Table 2 .

The mean age of the patients who had anterior circulation aneurysm was $44 \pm 16$ years, and this was $42 \pm 9$ years in those with posterior circulation aneurysms ( $\mathrm{P}$ value $=0.6)$. Among those patients who had aneurysm in the anterior circulation, $32(46.4 \%)$ were male and 37 (53.6\%) were female; these statistics were five (29.4\%) and $12(70.6 \%)$ for posterior circulation aneurysms ( $\mathrm{P}$ value $=$ $0.2)$.There was a significant association between the aneurysm size and gender $(\mathrm{P}$ value $=0.017)($ Table 3$)$.
Table 1. Demographic Data of Patients with Intracranial Aneurysms Treated by Coil ${ }^{\text {a }}$

\begin{tabular}{lc}
\hline Characteristics & No. (\%) \\
\hline Gender & \\
$\quad$ Male & $38(42.2)$ \\
\hline Female & $52(57.8)$ \\
\hline History of smoking & $18(20)$ \\
\hline History of hypertension & $31(34.4)$ \\
\hline History of hyperlipidemia & $15(16.7)$ \\
\hline History of CCU admission & $11(12.2)$ \\
History of CVA & $6(6.7)$ \\
CT Scan findings & \\
\hline Subarachnoid hemorrhage & $11(12.2)$ \\
\hline Intracranial hemorrhage & $2(2.2)$ \\
\hline Intraventricular hemorrhage & $2(2.2)$ \\
\hline Epidural hemorrhage & $2(2.2)$ \\
\hline Subdural hemorrhage & $2(2.2)$ \\
\hline Midline shift & $4(4.4)$ \\
\hline abbreviations: CCU, Cardiac Care Unit; and CVA, Cerebrovascular \\
accident
\end{tabular}

Table 2. Characteristics of Aneurysms According to Angiog

\begin{tabular}{|c|c|c|}
\hline \multirow{2}{*}{\multicolumn{2}{|c|}{$\begin{array}{l}\text { Characteristics } \\
\text { Location }\end{array}$}} & No. $(\%)$ \\
\hline & & \\
\hline \multicolumn{2}{|l|}{ ACA } & $6(6.7)$ \\
\hline \multicolumn{2}{|l|}{ ACOMA } & $18(20)$ \\
\hline \multicolumn{2}{|l|}{ MCA } & $4(4.4)$ \\
\hline \multicolumn{2}{|l|}{ PCA } & $4(4.4)$ \\
\hline \multicolumn{2}{|l|}{ PCOMA } & $3(3.3)$ \\
\hline \multicolumn{2}{|l|}{ ICA } & $38(42.2)$ \\
\hline \multicolumn{2}{|l|}{ Basilar } & $10(11.1)$ \\
\hline \multicolumn{2}{|l|}{ PICA } & $2(2.2)$ \\
\hline \multicolumn{2}{|c|}{ Superior cerebellar artery } & $1(1.1)$ \\
\hline \multicolumn{3}{|c|}{ Aneurysm size } \\
\hline \multicolumn{2}{|c|}{$<4 \mathrm{~mm}$} & $11(12.2)$ \\
\hline \multicolumn{2}{|c|}{ Between 4 and $10 \mathrm{~mm}$} & $44(48.9)$ \\
\hline \multicolumn{2}{|c|}{$>10 \mathrm{mmn}$} & $33(36.7)$ \\
\hline \multicolumn{3}{|c|}{ Aneurysm neck size } \\
\hline \multicolumn{2}{|l|}{$<4 \mathrm{~mm}$} & $27(30)$ \\
\hline \multicolumn{2}{|l|}{$\geq 4 \mathrm{~mm}$} & $41(45.6)$ \\
\hline \multicolumn{3}{|c|}{ Aneurysm shape } \\
\hline \multicolumn{2}{|l|}{ Fusiform } & $7(7.8)$ \\
\hline \multicolumn{2}{|c|}{ Saccular pedunculated } & $27(30)$ \\
\hline \multicolumn{2}{|c|}{ Saccular non-pedunculated } & $54(60)$ \\
\hline \multicolumn{3}{|c|}{$\begin{array}{l}\text { a Abbreviations: ACA, Anterior cerebral artery; ACOMA, Anterior } \\
\text { communicating artery; ICA, Internal carotid artery; MCA, Middle } \\
\text { cerebral artery; PCA, Posterior cerebral artery; PCOMA, Posterior } \\
\text { communicating artery; and PICA, Posterior inferior cerebellar artery }\end{array}$} \\
\hline \multicolumn{3}{|c|}{ Table 3. Association Between the Aneurysm Size and Gender a } \\
\hline Variables & $4-10 \mathrm{~mm}$ & $>10 \mathrm{~mm}$ \\
\hline Male & $16(36.4)$ & $12(36.4)$ \\
\hline Female & $28(63.6)$ & $21(63.6)$ \\
\hline Sum & $44(100)$ & $33(100)$ \\
\hline
\end{tabular}

${ }^{\mathrm{a}}$ Values are presented as No. (\%) 
Total occlusion was seen in 74 (82.2\%), subtotal occlusion in six (6.7\%), and partial occlusion in six patients (6.7\%) after the procedure (Figures 1-3).

There was no significant relationship between aneurysm size, aneurysm neck size, and location of the aneurysm with total or subtotal occlusions (Table 4).

\subsection{Complications}

Eleven patients (12.5\%) experienced complication during the procedure including two tears, three focal neurological signs, three vision disturbances, two mild to moderate vasospasms, and three bleedings in the aneurysm. There was no mortality during the procedure. Major complications were significantly higher in the posterior aneurysm compared to the anterior ones (55.6\% versus $44.4 \%$ of the major complications; OR=6.6 [95\% CI $=1.5$ 27.8, P value: 0.015$]$ ).

\subsection{Follow-Up}

Thirty-eight patients underwent control angiography in 6 months; among them, 34 patients (89.4\%) had no change in angiography, but two patients (5.3\%) had new growth and two subjects (5.3\%) had widening of the neck. Three patients (3.4\%) were dead in the six-month follow-up.

There was no statistical association between the aneu- rysm size and the results of coiling after six months ( $\mathrm{P}$ value $=0.57$ ). We did not find any statistical association between the shape of the aneurysm and total, sub-total or partial occlusion in our patients (P value $=0.84$ ).

While, regarding the aneurysm neck size, one patient with any change in control angiography had the aneurysm neck of lower than $4 \mathrm{~mm}$ and three had the aneurysm neck of greater than $4 \mathrm{~mm}(\mathrm{P}$ value $=0.3)$. Among the 27 patients with an aneurysm neck size lower than 4 $\mathrm{mm}$, only one patient experienced complication (3.7\%), while this percent was $21.2 \%$ (seven patients) among those with a neck size greater than $4 \mathrm{~mm}(\mathrm{P}=0.1)$.

There was no statistical association between the complication and shape of aneurysms $(P=1)$. The frequency of complications in the posterior circulation aneurysms was $29.4 \%$ ( 5 of 17 ), while this was $5.9 \%$ among the anterior ones ( 4 of 67$)(\mathrm{P}=0.01)$.

The mean age of patients with subtotal occlusion was significantly higher than the mean age of cases with total occlusion $(44 \pm 14$ years versus $53 \pm 10$; P value $=0.04$ ). There was no significant association between location of the aneurysms and recurrence rate $(P$ value $=0.5$ ).

Although aneurysms that remained unchanged after six months follow-up angiography had total occlusion after the procedure, this was $50 \%$ for those aneurysms that had any changes in 6 months follow up angiography $(\mathrm{P}$ value $=0.01$.
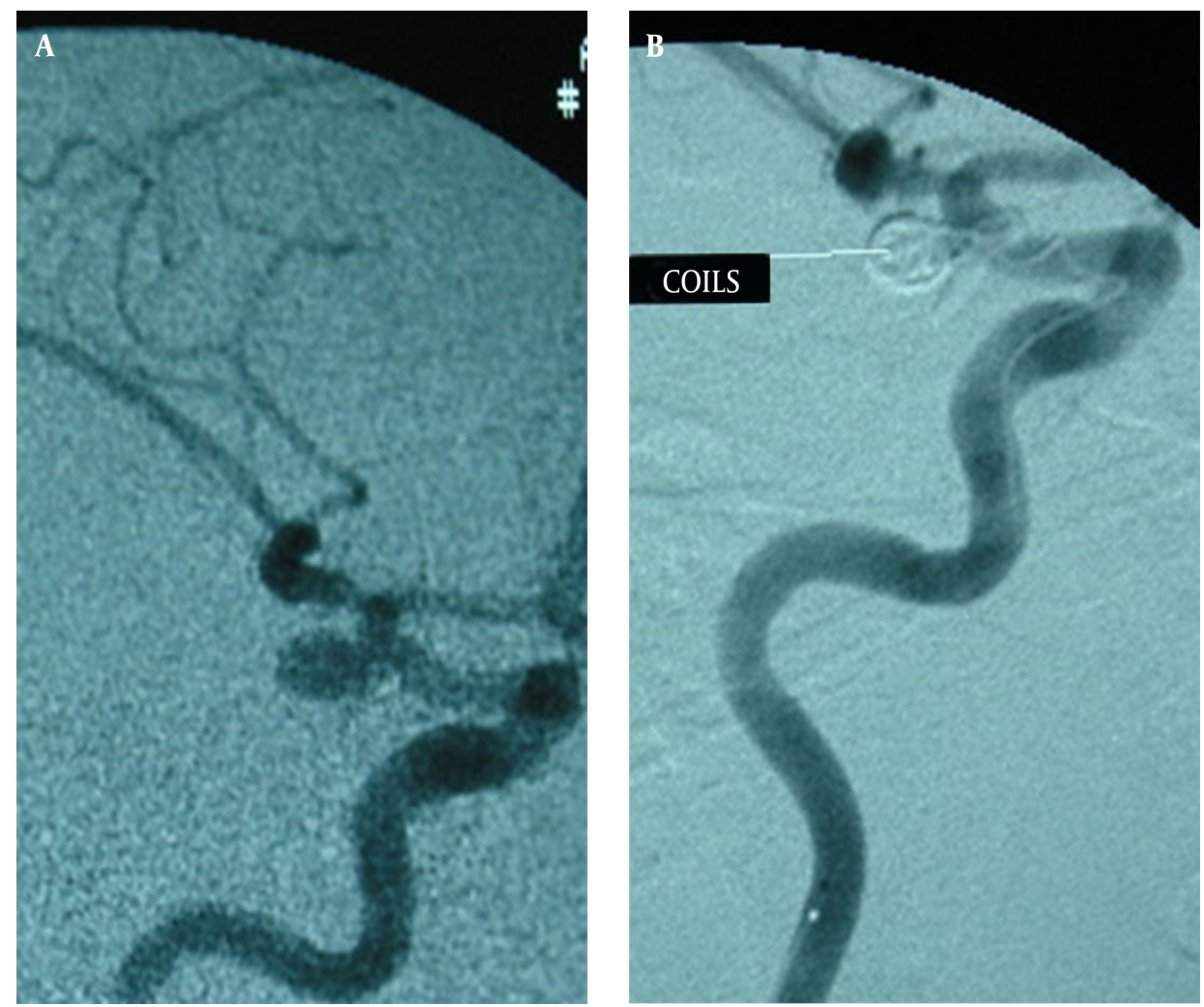

Figure 1. Total coil embolization in a 49-year-old man with right internal carotid artery aneurysm. A, Before coil embolization. B, After coil embolization 
Miri M et al.
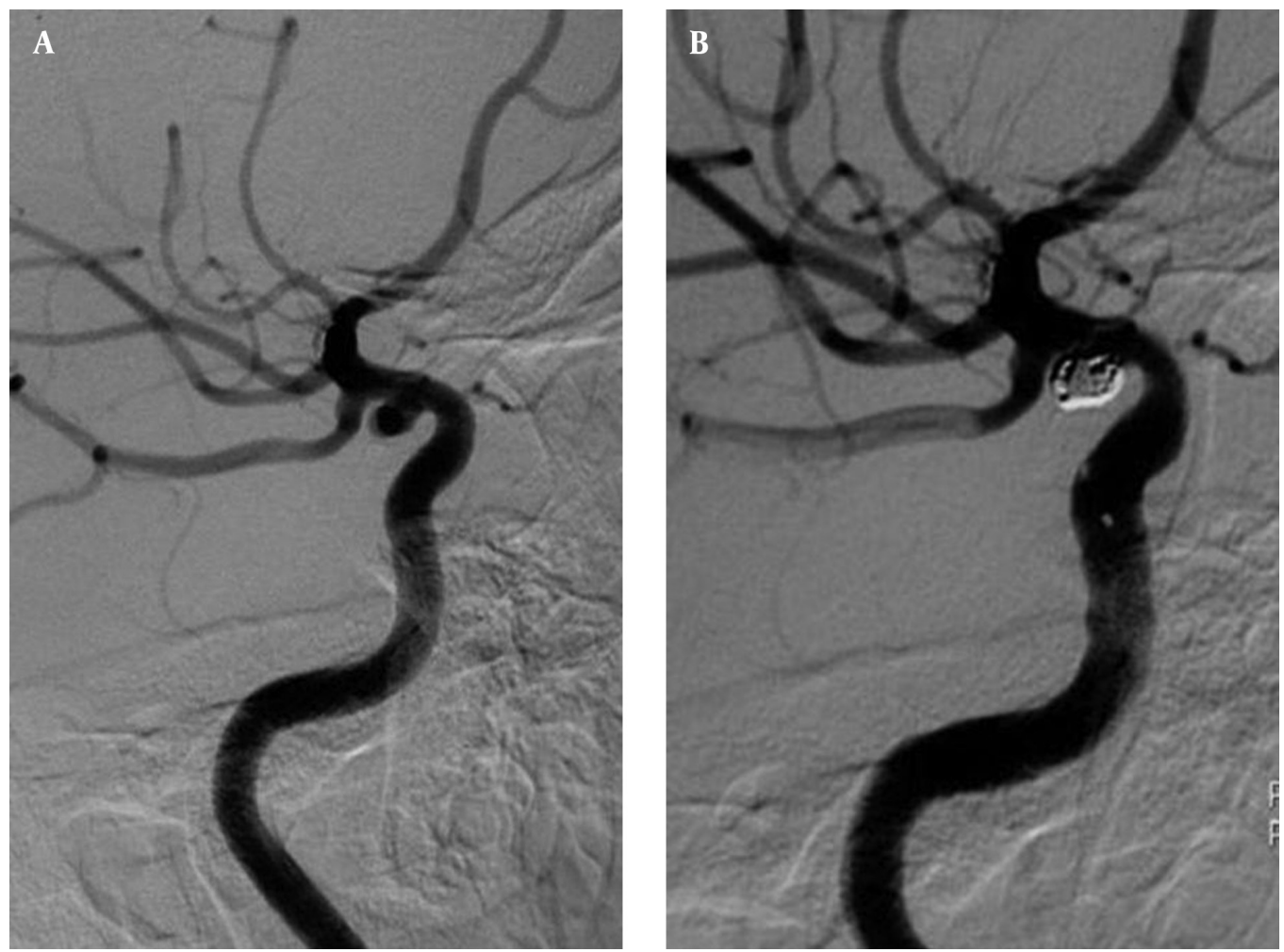

Figure 2. Subtotal coil embolization in a 47-year-old man with right internal carotid artery aneurysm. A, Before coil embolization. B, After coil embolization
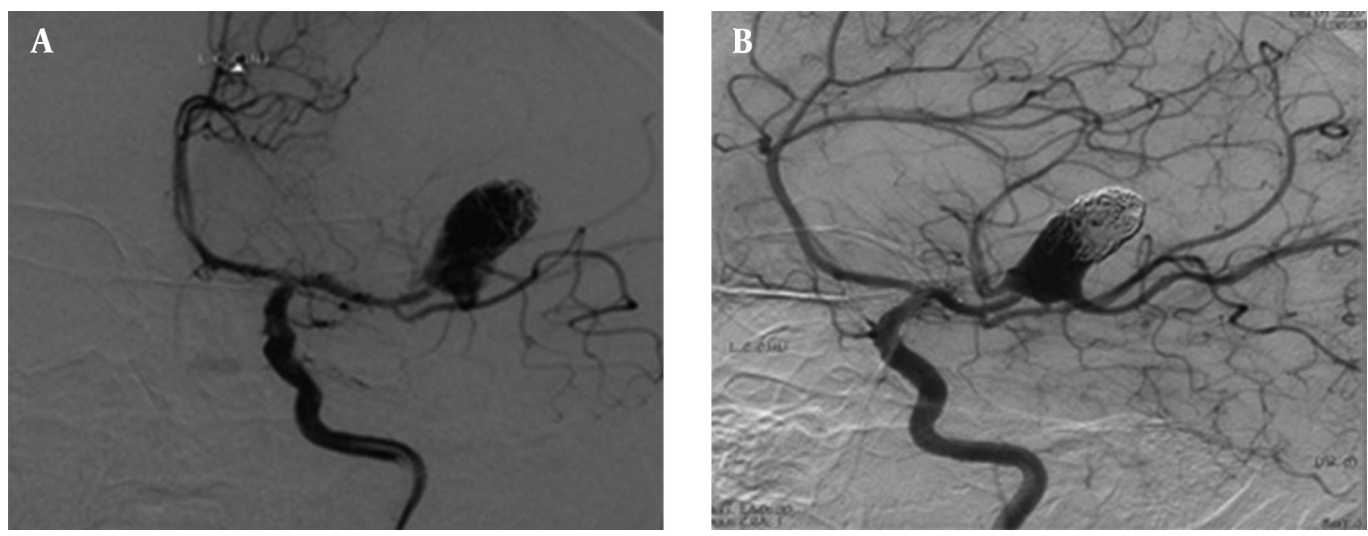

Figure 3. Partial coil embolization in a 52-year-old man with left MCA wide neck aneurysm. A, Before coil embolization. B, After coil embolization

\begin{tabular}{|c|c|c|c|}
\hline Variables & Total Occlusion $^{\mathrm{a}}$ & Subtotal Occlusion $^{\mathrm{a}}$ & P Value \\
\hline Location & & & 0.6 \\
\hline Anterior circulation & $58(87.9)$ & $8(12.1)$ & \\
\hline Posterior circulation & $14(82.4)$ & $3(17.6)$ & \\
\hline Aneurysm size, $\mathrm{mm}$ & & & 0.1 \\
\hline$<10$ & $47(90.4)$ & $5(9.6)$ & \\
\hline$\geq 10$ & $25(78.1)$ & $7(21.9)$ & \\
\hline Size of the aneurysm neck, $\mathrm{mm}$ & & & 0.9 \\
\hline$\geq 4$ & $34(85)$ & $6(15)$ & \\
\hline$<4$ & 22 (91.7) & $2(8.3)$ & \\
\hline
\end{tabular}

\footnotetext{
a Values are presented as No (\%)
} 


\section{Discussion}

One of the most vital and disabling outcomes associated with ruptured intracranial aneurysms is rebleeding; thus, early surgical or endovascular treatment is recommended (9). Coil embolization is an established therapeutic procedure for both ruptured and unruptured intracranial aneurysms, and in many centers, this procedure is recommended as the first treatment option (8, $10,11)$. However, ruptured wide-necked or fusiform aneurysms are the most difficult challenges (12). All the series in the literature report low morbidity and mortality rates of endovascular therapies, and both of them decrease as the physician's experience increases (13-15).

In our study, aneurysms treated by endovascular coil embolization showed a favorable outcome with an acceptable procedure-related morbidity rate. There were a few complications through coiling. In a multicenter study of detachable coil on 705 aneurysms, 422 aneurysms (73.9\%) demonstrated complete occlusion, 148 aneurysms (25.9\%) demonstrated subtotal occlusion, and only one aneurysm was incompletely occluded. The overall mortality was $11.4 \%$ for all patients, with procedural mortality evaluated as $1.4 \%$ (16).

D'Agostino et al. (17) performed a clinical experience with coils in the treatment of 100 intracranial aneurysms. In their study, the follow-up was done at 6 and 12 months. Initial complete occlusion was obtained in 80 aneurysms. Of the 76 aneurysms with a 6-month angiographic followup, four (5.3\%) revealed further occlusion, 54 (71.1\%) were unchanged, and 18 (23.7\%) showed recanalization. Sixand 12-month angiograms showed major recanalization (requiring further coiling) in 3.9\% and 15.8\% of the cases, respectively. Our results after six months were approximately similar to the study conducted by D'Agostino et al. we had good results in a six-month follow-up with a $89.4 \%$ success rate and only three deaths (17).

Several long-term follow-up studies of patients with coiled aneurysms have supported an optimal long-term follow-up protocol in preventing subsequent SAH (18). The most important indication for imaging follow-up after coiling is to evaluate the reopening. There is an increased risk of recurrent SAH in long term in those patients who have incomplete occlusion after coiling, and in such cases re-treatment is recommended. In addition, in unhealthy intracranial arteries, new aneurysms may develop and cause recurrent SAH (18).

In a study on 126 patients with angiographic follow-up studies at 6 and 18 months after coiling, all reopenings were found at 6-month angiography (19). Aneurysms that were sufficiently occluded at 6 months stayed so at 18 months, and there were no recurrences after 6 months.

If there is more first-time recurrences in longer followup angiographies, extended imaging follow-up would be essential to detect these recurrences. Furthermore, if there is adequately occluded aneurysm at 6 months that have not reopened later, extended follow-up is not required. Long-term follow-up studies have been performed focusing on patients with coiled aneurysms that were sufficiently occluded at 6-month angiographic follow-up to explain this problem.

These studies show that in the group of patients with coiled aneurysms that are sufficiently occluded at 6 months, the risk of first-time reopening that needs retreatment in the first 5-10 years after coiling is very low, and all aneurysm reopenings occur in the first 6 months after coiling (19).

Recanalization of the aneurysms treated with coils depends on factors including the aneurysm size, neck diameter, aneurysm location, and history of rupture (2022). There is a higher re-treatment rate in studies with aneurysms larger than $10 \mathrm{~mm}$ in size (23). However, in our study, only the aneurysm location was statistically associated with recanalization.

As we found in our study, patients with posterior circulation aneurysms had higher incompletely occluded aneurysms at follow-up and higher reopening rate in comparison with the patients with anterior circulation aneurysms (18\% versus $12 \%$ ), which was similar to other studies $(24,25)$.

A possible reason is that surgery is less likely indicated in posterior circulation aneurysms. Therefore, posterior circulation aneurysms with unfavorable shapes are coiled, while aneurysms with unfavorable shapes in the anterior circulation are clipped surgically. Considering the results of the previous studies and ours, when there is a completely coiled aneurysm after the procedure, the bleeding risk of that aneurysm is very low (26).

Stable obliteration of the lumen after aneurysm packing depends on the amount of luminal occlusion and a tight mass of coils (27). Regrowth of the neck or proximal body may occur due to incomplete occlusion and it is more common in proximal aneurysms (27). Partial occlusion of the aneurysm lumen may cause a higher recurrence rate and re-rupture, and our results confirm this.

There were limitations in our study such as limited number and limited period of angiographic follow-up of this study, which may have lowered the recurrence rate. It is recommended to perform further studies with longer follow-up periods to clarify the risk of recanalization after aneurysm coiling. In conclusion, this study showed successful outcomes in the treatment of intracranial aneurysms with a low complication rate.

\section{Authors' Contributions}

Mojtaba Miri: study concept and design, acquisition of data, and study supervision. Hossein Ghanaati: study concept and design, acquisition of data, and study supervision. Payman Salamati: study concept and design, study supervision, analysis, and interpretation of data. Hojat Ebrahimi Nik: study concept and design, acquisition of data, study supervision, and drafting of the manuscript. Amir Hossein Jalali: analysis and interpretation of data, 
drafting of the manuscript, and acquisition of data. Mina Saeednejad: analysis and interpretation of data, drafting of the manuscript, and acquisition of data. Kavous Firouznia: study concept and design, acquisition of data, and study supervision.

\section{Funding/Support}

This study was funded and supported by Tehran University of Medical Sciences (TUMS); Grant number 114.

\section{References}

1. Hop JW, Rinkel GJ, Algra A, van Gijn J. Case-fatality rates and functional outcome after subarachnoid hemorrhage: a systematic review. Stroke. 1997;28(3):660-4.

2. Linn FH, Rinkel GJ, Algra A, van Gijn J. Incidence of subarachnoid hemorrhage: role of region, year, and rate of computed tomography: a meta-analysis. Stroke. 1996;27(4):625-9.

3. Molyneux A, Kerr R, International Subarachnoid Aneurysm Trial Collaborative G, Stratton I, Sandercock P, Clarke M, et al. International Subarachnoid Aneurysm Trial (ISAT) of neurosurgical clipping versus endovascular coiling in 2143 patients with ruptured intracranial aneurysms: a randomized trial. J Stroke Cerebrovasc Dis. 2002;11(6):304-14.

4. Lee SJ, Cho YD, Kang HS, Kim JE, Han MH. Coil embolization using the self-expandable closed-cell stent for intracranial saccular aneurysm: A single-center experience of 289 consecutive aneurysms. Clinical Radiology. 2013;68(3):256-63.

5. Molyneux AJ, Kerr RS, Yu LM, Clarke M, Sneade M, Yarnold JA, et al. International subarachnoid aneurysm trial (ISAT) of neurosurgical clipping versus endovascular coiling in 2143 patients with ruptured intracranial aneurysms: a randomised comparison of effects on survival, dependency, seizures, rebleeding, subgroups, and aneurysm occlusion. The Lancet. 2005;366(9488):809-17.

6. Vinuela F, Duckwiler G, Mawad M. Guglielmi detachable coil embolization of acute intracranial aneurysm: perioperative anatomical and clinical outcome in 403 patients. J Neurosurg. 1997;86(3):475-82.

7. Byrne JV, Sohn MJ, Molyneux AJ, Chir B. Five-year experience in using coil embolization for ruptured intracranial aneurysms: outcomes and incidence of late rebleeding. J Neurosurg. 1999;90(4):656-63.

8. Molyneux A. International Subarachnoid Aneurysm Trial (ISAT) of neurosurgical clipping versus endovascular coiling in 2143 patients with ruptured intracranial aneurysms: a randomised trial. The Lancet. 2002;360(9342):1267-74.

9. Liu JM, Huang QH, Xu Y, Hong B, Zhang L, Zhang X. Combined stent and coil in endovascular treatment of intracranial wide-necked and fusiform aneurysms. Chin Med J (Engl). 2004;117(1):54-7.

10. Brilstra EH, Rinkel GJ, van der Graaf Y, van Rooij WJ, Algra A. Treatment of intracranial aneurysms by embolization with coils: a systematic review. Stroke. 1999;30(2):470-6

11. Gallas S, Januel AC, Pasco A, Drouineau J, Gabrillargues J, Gaston A, et al. Long-term follow-up of 1036 cerebral aneurysms treated by bare coils: a multicentric cohort treated between 1998 and 2003. AJNR Am J Neuroradiol. 2009;30(10):1986-92.

12. Hoh BL, Putman CM, Budzik RF, Carter BS, Ogilvy CS. Combined surgical and endovascular techniques of flow alteration to treat fusiform and complex wide-necked intracranial aneurysms that are unsuitable for clipping or coil embolization. J Neurosurg. 2001;95(1):24-35.

13. Debrun GM, Aletich VA, Kehrli P, Misra M, Ausman JI, Charbel F. Selection of cerebral aneurysms for treatment using Guglielmi detachable coils: the preliminary University of Illinois at Chicago experience. Neurosurgery. 1998;43(6):1281-95.

14. Fernandez Zubillaga A, Guglielmi G, Vinuela F, Duckwiler GR. Endovascular occlusion of intracranial aneurysms with electrically detachable coils: correlation of aneurysm neck size and treatment results. AJNR Am J Neuroradiol. 1994;15(5):815-20.

15. Debrun GM, Aletich VA, Thornton J, Alazzaz A, Charbel FT, Ausman JI, et al. Techniques of coiling cerebral aneurysms. Surg Neurol. 2000;53(2):150-6.

16. Gallas S, Pasco A, Cottier JP, Gabrillargues J, Drouineau J, Cognard C, et al. A multicenter study of 705 ruptured intracranial aneurysms treated with Guglielmi detachable coils. AJNR Am J Neuroradiol. 2005;26(7):1723-31.

17. D'Agostino SJ, Harrigan MR, Chalela JA, Nicholas JS, Deveikis SI, Jones TM, et al. Clinical experience with Matrix2 360 degrees coils in the treatment of 100 intracranial aneurysms. Surg Neurol. 2009;72(1):41-7.

18. van Rooij WJ, Sluzewski M. Opinion: imaging follow-up af ter coiling of intracranial aneurysms. AJNR Am J Neuroradiol. 2009;30(9):1646-8.

19. Sluzewski M, van Rooij WJ, Rinkel GJ, Wijnalda D. Endovascular treatment of ruptured intracranial aneurysms with detachable coils: long-term clinical and serial angiographic results. Radiology. 2003;227(3):720-4.

20. Grunwald IQ, Papanagiotou P, Struffert T, Politi M, Krick C, Gul G et al. Recanalization after endovascular treatment of intracerebral aneurysms. Neuroradiology. 2007;49(1):41-7.

21. Pandey AS, Koebbe C, Rosenwasser RH, Veznedaroglu E. Endovascular coil embolization of ruptured and unruptured posterior circulation aneurysms: review of a 10-year experience. Neurosurgery. 2007;60(4):626-36.

22. Raymond J, Guilbert F, Weill A, Georganos SA, Juravsky L, Lambert A, et al. Long-term angiographic recurrences after selective endovascular treatment of aneurysms with detachable coils. Stroke. 2003;34(6):1398-403.

23. Ferns SP, Sprengers ME, van Rooij WJ, Rinkel GJ, van Rijn JC, Bipat $S$, et al. Coiling of intracranial aneurysms: a systematic review on initial occlusion and reopening and retreatment rates. Stroke. 2009;40(8):e523-9.

24. Campi A, Ramzi N, Molyneux AJ, Summers PE, Kerr RS, Sneade M, et al. Retreatment of ruptured cerebral aneurysms in patients randomized by coiling or clipping in the International Subarachnoid Aneurysm Trial (ISAT). Stroke. 2007;38(5):1538-44.

25. Peluso JP, van Rooij WJ, Sluzewski M, Beute GN. Coiling of basilar tip aneurysms: results in 154 consecutive patients with emphasis on recurrent haemorrhage and re-treatment during mid- and long-term follow-up. J Neurol Neurosurg Psychiatry. 2008;79(6):706-11.

26. Choi DS, Kim MC, Lee SK, Willinsky RA, Terbrugge KG. Clinical and angiographic long-term follow-up of completely coiled intracranial aneurysms using endovascular technique. J Neurosurg. 2010;112(3):575-81.

27. Byrne JV, Adams CB, Kerr RS, Molyneux AJ. Endosaccular treatment of inoperable intracranial aneurysms with platinum coils. BrJ Neurosurg. 1995;9(5):585-92. 